\title{
A Heat Transfer Model for a Stratified Corium-Metal Pool in the Lower Plenum of a Nuclear Reactor
}

\author{
M. S. Sohal \\ L. J. Siefken
}

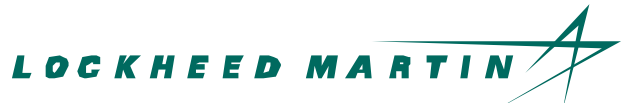




\title{
A Heat Transfer Model for a Stratified Corium-Metal Pool in the Lower Plenum of a Nuclear Reactor
}

\author{
M. S. Sohal \\ L. J. Siefken \\ Published August 1999 \\ Idaho National Engineering and Environmental Laboratory \\ Lockheed Martin Idaho Technologies Company \\ Idaho Falls, Idaho 83415
}

Prepared for the

U.S. Nuclear Regulatory Commission

Washington, DC 20555 


\begin{abstract}
This preliminary design report describes a model for heat transfer in a coriummetal stratified pool. It was decided to make use the existing COUPLE model. Currently available correlations for natural convection heat transfer in a pool with and without internal heat generation were obtained. The appropriate correlations will be incorporated in the existing COUPLE model. Heat conduction and solidification modeling will be done with existing algorithms in the COUPLE. Assessment of the new model will be done by simple energy conservation problems.
\end{abstract}




\section{CONTENTS}

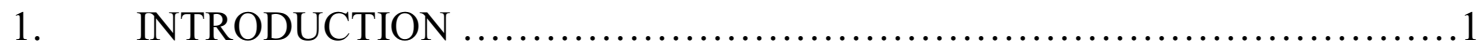

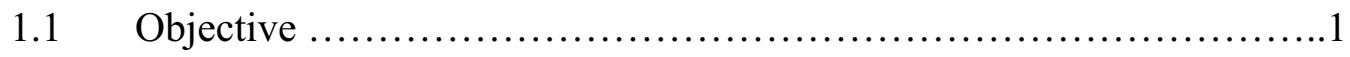

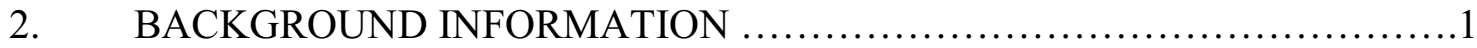

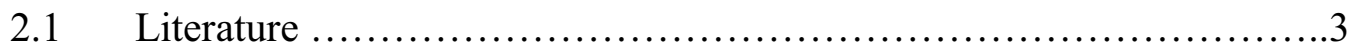

2.1.1 Natural Convection in a Pool with Internal Heat Generation .....4

2.1.2 Natural Convection in a Pool without Internal Heat Generation ..9

3. SELECTED NUSSELT NO. VERSUS RAYLEIGH NO. CORRELATIONS .10

4. IMPLEMENTATION OF STRATIFIED HEAT TRANSFER MODEL INTO

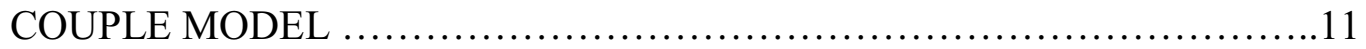

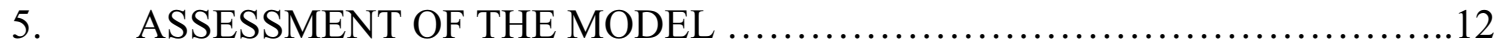

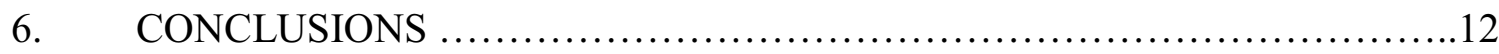

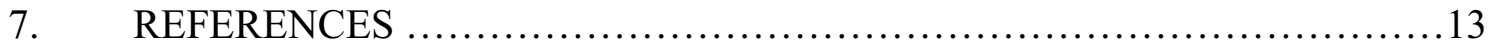




\section{FIGURES}

Figure 1 Schematic drawing of corium and metal pools in the lower head .....2

Figure 2 Nu versus $\mathrm{Ra}^{\prime}$ correlations based on Steinberner and Reineke ${ }^{6}$ data ...5

Figure 3 Upward heat transfer data correlation by Theofanous et al. ${ }^{8} \ldots \ldots \ldots . .5$

Figure 4 Downward heat transfer data correlation by Theofanous et al. ${ }^{8} \ldots \ldots . .7$

Figure 5 Correlation (Equation 8 and 9) of mini-ACOPO data for downward heat

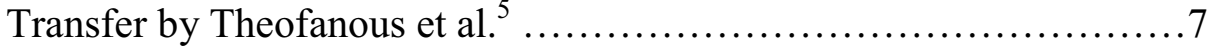

Figure 6 Comparison of Equation (10) predictions with experimental data and numerical results for downward heat transfer ${ }^{5} \ldots \ldots \ldots \ldots \ldots \ldots \ldots . . . \ldots$

Figure 7 Comparison of Equation (10) predictions with ACOPO data for downward

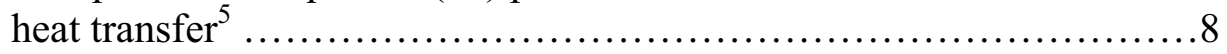

Figure 8 Natural convection upward heat transfer data and correlation by Park et al. $^{13}$....................................................... 10 


\section{TABLES}

Table $1 \quad$ Selected Nu vs. Ra Correlations ..................................10 


\section{EXECUTIVE SUMMARY}

The objective of this design report is to develop a model for heat transfer in stratified corium and metal pools in a nuclear reactor lower head formed as a result of severe accident. Natural convection heat transfer correlations in pools with and without internal heat generation were obtained from existing literature. It was decided to make use of the existing COUPLE model and its algorithm to reduce the coding cost. The appropriate correlations will be incorporated in the COUPLE model. Heat conduction and solidification modeling will be done with existing algorithms in the COUPLE. The new model will be assessed by energy conservation and other simple test problems, because no exact experimental data are available. 


\section{INTRODUCTION}

The SCDAP/RELAP5 ${ }^{1}$ computer code is designed to describe the overall nuclear reactor coolant system thermal-hydraulic response and core damage progression. The SCDAP code models the core behavior and RELAP5 calculates the thermal hydraulics during a severe accident. The code is being developed at the Idaho National Engineering and Environmental Laboratory (INEEL) under the sponsorship of U. S. Nuclear Regulatory Commission (NRC). In a severe accident scenario, the fuel and metal components such as cladding and core plate may melt and slump into the lower head of the reactor vessel. To avoid melting or structural failure of the lower vessel, some reactors are designed to have the lower head submerged in a pool of water in the event of a severe accident. Thus, heat generated inside is vessel is transferred to the water outside the vessel. To calculate the temperature of the vessel wall, the heat transfer from the molten material pool to the vessel walls has to be calculated. This report discusses the heat transfer model for heat transfer in the lower head after a severe accident when the fuel, fuel-cladding material, and metal components have slumped and settled in the lower head.

\subsection{Objective}

The multi-component and multi-phase mixture consisting of fuel, cladding, other metal and water in the lower head may form a homogeneous mixture or may stratify in two distinct layers. If the mixture stratifies, the upper layer may consist of lighter component of molten metal and the lower heavier layer may consist of corium (mixture of $\mathrm{ZrO}_{2}$ and $\mathrm{UO}_{2}$ ). The corium mixture is also the source of volumetric heat generation. Under certain thermal conditions, a crust of solid material may also form along the vessel wall and on the top of the layer containing corium mixture. The objective of this report is to develop a model to account for heat transfer from the mixture in the vessel to the vessel wall and to the environment lying above the upper layer under the given possible physical conditions. A model will be developed based on the available correlations for natural convection heat transfer in a hemispherical geometry.

\section{BACKGROUND INFORMATION}

During a TMI-2 like hypothetical nuclear reactor accident, the molten core relocates to the lower head. When the molten fuel interact with the coolant in the lower head, the fuel breaks up into small debris and eventually settle down on the bottom. Lighter molten metal may separate into a layer and settle on top of the corium volume as shown in Figure 1. The volumetric heat generation in the corium dissipates through the vessel wall by conduction and by radiates to the vessel volume above. The resulting temperature gradient in the liquid pool consisting of corium and molten metal will generate natural convection currents. Researchers have developed correlations for natural convection in hemispherical and cylindrical pools. Some of the basic phenomena and applicable correlations are reviewed in the following. 


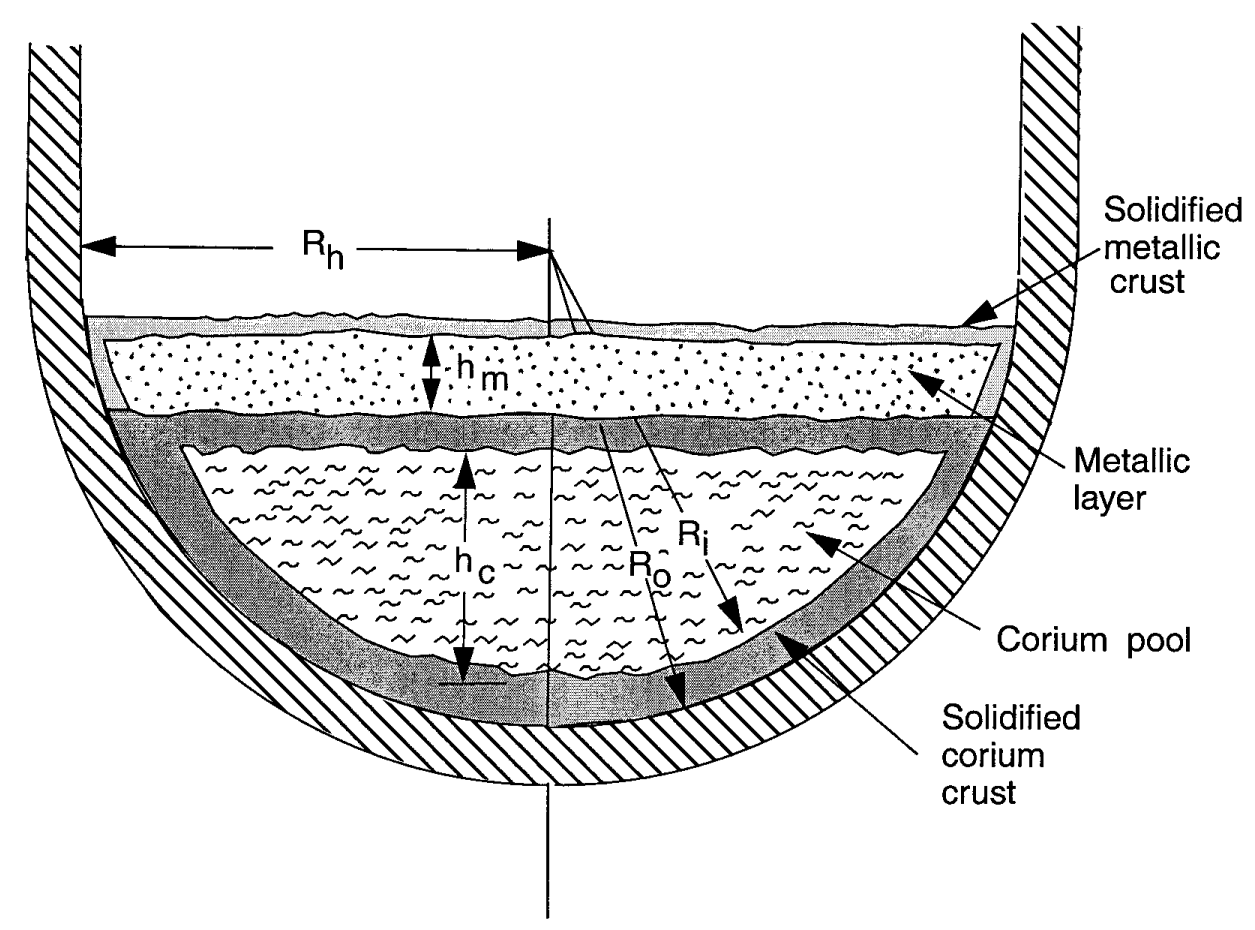

Figure 1. Schematic drawing of corium and metal pools in the lower head.

When a liquid pool is heated, the buoyant and viscous forces act in opposite directions on a fluid volume. The ratio of buoyant and viscous forces times the ratio of convective and conduction heat transfer is the characteristic dimensionless parameter and is called Rayleigh number. If the liquid volume is heated by external means, this number is called "external" Rayleigh number and is denoted by Ra. If the heating is caused by internal volumetric heat generation, this number is called "internal" or "modified" Rayleigh number, $\mathrm{Ra}^{\prime}$. These two dimensionless numbers, $\mathrm{Ra}$ and $\mathrm{Ra}^{\prime}$, are defined as $\frac{g \beta \Delta T L^{3}}{\alpha v}$ and $\frac{g \beta \dot{q}_{v} L^{5}}{\alpha v k}$, respectively,

where
$\mathrm{g}=$ acceleration due to gravity $\left(\mathrm{m} / \mathrm{s}^{2}\right)$,
$\beta=\quad$ coefficient of thermal expansion $(1 / \mathrm{K})$,
$\Delta \mathrm{T}=\quad$ Temperature difference between bulk liquid and the boundary $(\mathrm{K})$,
$\mathrm{q}_{\mathrm{v}} \cdot \quad=\quad$ volumetric heat generation rate $\left(\mathrm{W} / \mathrm{m}^{3}\right)$,
$\mathrm{L}=$ characteristic length $(\mathrm{m})$, 


$$
\begin{array}{lll}
\alpha & = & \text { thermal diffusivity }\left(\mathrm{m}^{2} / \mathrm{s}\right), \\
v & = & \text { kinematic viscosity }\left(\mathrm{m}^{2} / \mathrm{s}\right), \\
\mathrm{k} & = & \text { thermal conductivity }(\mathrm{W} / \mathrm{m} \cdot \mathrm{K}) .
\end{array}
$$

All the properties correspond to the fluid in question. Various researchers have used different values for the characteristic length. These values are: (1) the maximum radius of the liquid surface at the top of the pool, (2) maximum depth of the liquid pool, (3) an average of the maximum pool radius and the pool depth, and (4) radius of an equivalent hemispherical pool. In a correlation for Nusselt number, $\mathrm{Nu}=\mathrm{a}\left(\mathrm{Ra}^{\prime} \mathrm{b}\right)$, where $\mathrm{b} \approx 0.2$, the characteristic length will cancel from the two sides and will not make any significant difference to the value of convective heat transfer coefficient, h. However, if $\mathrm{b}$ (for $7 \cdot 10^{6} \leq \mathrm{Ra}^{\prime} \leq 5 \cdot 10^{14}$ ) has a value far different than 0.2 , and the liquid pool is not nearly hemispherical (either shallow or deep), then different definitions of characteristic lengths can effect the value of convective heat transfer coefficient. Therefore, except for a shallow molten metallic layer above corium pool, an average of liquid pool radius and pool height will be used.

The two Rayleigh numbers are related by a correlation

$$
\begin{aligned}
& R a^{\prime}=R a\left(\frac{\dot{q}_{v} L^{2}}{k \Delta T}\right) \\
& \text { where } \frac{\dot{q}_{v} L^{2}}{k \Delta T} \text { is called Damköhler number. }
\end{aligned}
$$

\subsection{Literature}

After nuclear reactor core material slumps into the lower plenum, it goes through a significant amount of relocation and energy exchange. The entire molten pool of corium and metallic components may be treated as a homogeneous mixture as currently modeled in SCDAP. The corium and metallic components may stratify forming a lower corium pool with metallic layer settling on the top. With time, each layer will get cooled and a solid crust of corium and metal may form around the respective liquid pools. The upper metal layer and lower corium pool also exchange energy with one another, which couples the energy balance in the two layers.

At present no well-accepted criterion or correlation exists that can determine whether there is one homogeneous liquid pool or two stratified pools. Therefore, the SCDAP user has to decide whether to model the liquid pool as one homogeneous pool or as two stratified layers.

Kelkar et al. ${ }^{2}$ and Schmidt et al. ${ }^{3}$ performed numerical analysis of natural convection in a hemispherical cavity. Kelkar et al. ${ }^{2}$ also summarized several correlations 
for natural convection in enclosures. Similarly, Wang and Walton ${ }^{4}$ also examined applicability of several correlations for natural convection in enclosures and developed the relationship between external and internal Rayleigh numbers. Theofanous et al. ${ }^{5}$ have also examined the natural convection phenomenon in a hemispherical part of the reactor vessel. They examined both oxidic and metallic pools, and respective applicable natural convection correlations. The correlations given below for various physical conditions are based on the discussion given in these publications.

\subsubsection{Natural Convection in a Pool with Internal Heat Generation}

One of the useful correlations for natural convection was developed by Steinberner and Reineke ${ }^{6}$. They performed experiments with rectangular geometry with both upper and lower walls being cooled. Numerical modeling was used to develop Nusselt number, $\mathrm{Nu}$, correlations for natural convection heat transfer in the upward and downward directions as shown in Figure 2. These correlations are given below. Subscripts u and d represent upward and downward heat transfer directions, respectively.

$$
\begin{array}{ll}
\mathrm{Nu}_{\mathrm{u}}=0.345 \mathrm{Ra}^{\prime 0.233} & \left(\text { for } 10^{10} \leq \mathrm{Ra}^{\prime} \leq 3.7 \cdot 10^{13}\right) \\
\mathrm{Nu}_{\mathrm{d}}=1.389 \mathrm{Ra}^{\prime 0.095} & \left(\text { for } 10^{10} \leq \mathrm{Ra}^{\prime} \leq 3.7 \cdot 10^{13}\right)
\end{array}
$$

Kymäläinen et al. ${ }^{7}$ performed experiments, in a facility called COPO (or mini ACOPO), on the heat flux distributions at the boundaries of a volumetrically heated pool with high Rayleigh numbers to simulate molten corium pool in a reactor vessel. The experimental facility consisted of a two-dimensional slice (of a hemispherical cavity) filled with $\mathrm{H}_{2} \mathrm{O}-\mathrm{ZnSO}_{4}$. Their results showed that the upward heat flux to the top boundary is somewhat conservatively represented by the relationship given by

Steinberner and Reineke ${ }^{6}$ in Equation (3). Their data showed the applicability of Equation (3) for a $\mathrm{Ra}^{\prime}$ up to $6 \cdot 10^{14}$. For the vertical side walls, another correlation by Steinberner and Reineke ${ }^{6}$ (Figure 2) fits the horizontal heat flow data satisfactorily. This is given in Equation (4);

$$
\mathrm{Nu}_{\mathrm{h}}=0.85 \mathrm{Ra}^{\prime 0.19} \quad\left(\text { for } 5 \cdot 10^{12} \leq \mathrm{Ra}^{\prime} \leq 10^{14}\right) .
$$

This relation is applicable only in the turbulent flow regime, which is usually the case for corium pool. For a laminar flow regime, the only change from Equation (4) is that the numerical coefficient on the right hand side of Equation (4) changes to 0.6 as shown in Equation (5);

$$
\mathrm{Nu}_{\mathrm{h}}=0.6 \mathrm{Ra}^{\prime 0.19} \quad\left(\text { for } 10^{7} \leq \mathrm{Ra}^{\prime} \leq 10^{10}\right) .
$$




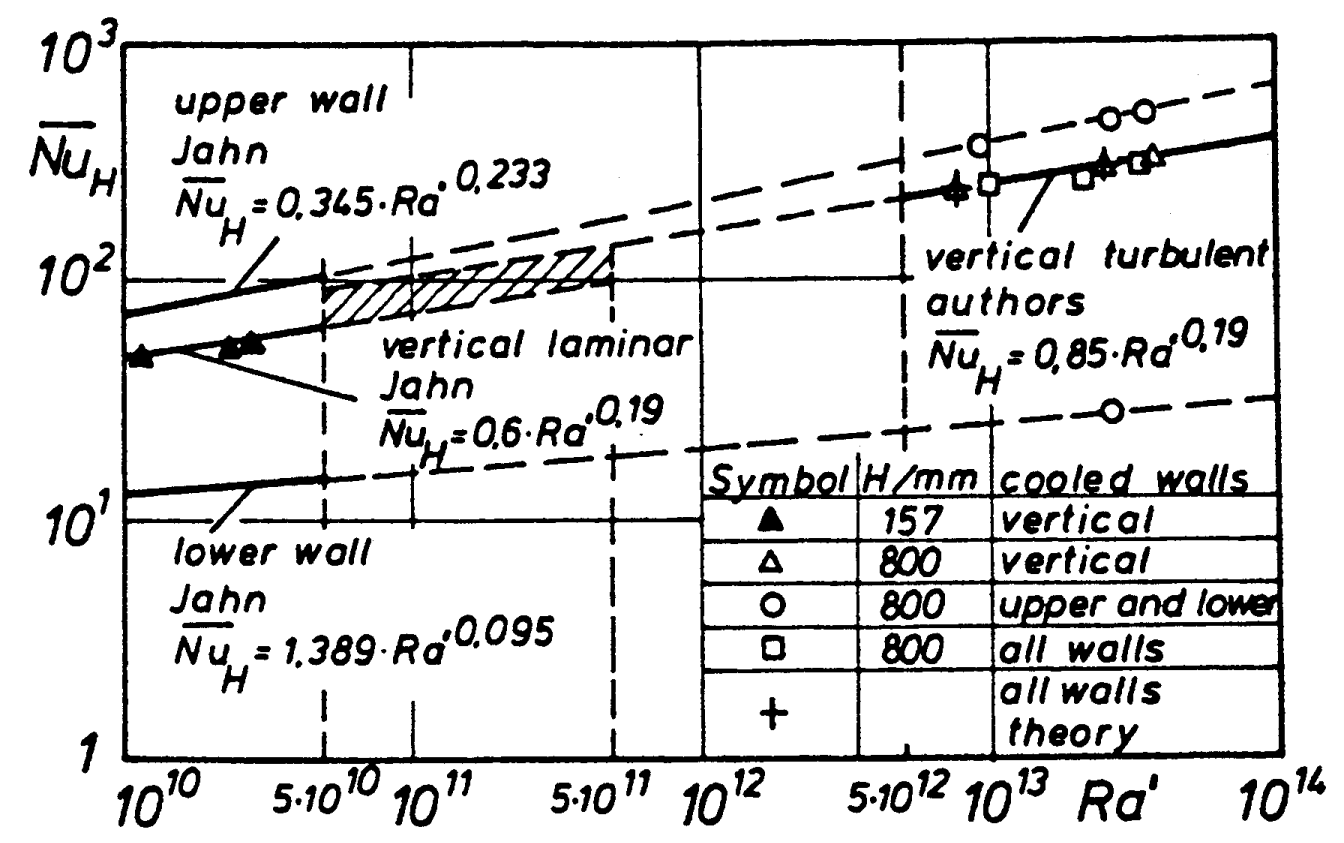

Figure 2. Nu versus $\mathrm{Ra}^{\prime}$ correlations based on data of Steinberner and Reineke ${ }^{6}$.

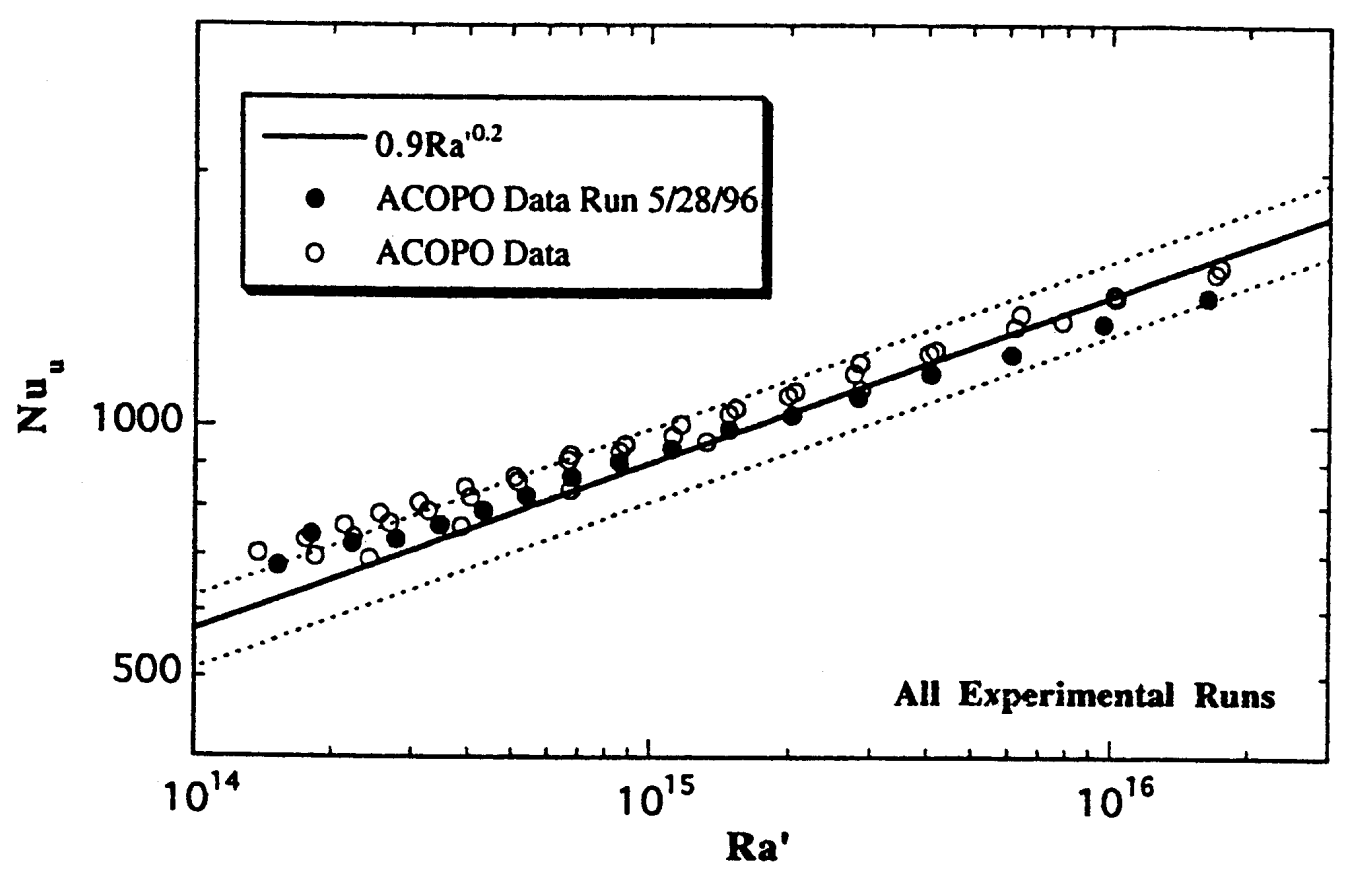

Figure 3. Upward heat transfer data correlation by Theofanous et al. ${ }^{8}$ 
Theofanous et al. ${ }^{8}$ performed further experiments in a hemispherical facility called ACOPO, to measure heat transfer data. The upward heat transfer was compared with Steinberner and Reineke ${ }^{6}$ correlation (Equation 2). It was determined that as $\mathrm{Ra}^{\prime}$ reaches a high value in the range $10^{15}-10^{16}$, Equation (2) deviates more and more from the ACOPO data. Therefore, Theofanous et al. ${ }^{8}$ correlated the ACOPO data by the correlation given in Equation (6), which is compared with the data in Figure (3);

$$
\mathrm{Nu}_{\mathrm{u}}=0.9 \mathrm{Ra}^{0.2} \quad\left(\text { for } 10^{14} \leq \mathrm{Ra}^{\prime} \leq 10^{17}\right. \text { ). }
$$

For downward heat transfer, Theofanous et al. ${ }^{8}$ correlated their ACOPO data by the following correlation, as shown in Figure 4;

$$
\mathrm{Nu}_{\mathrm{d}}=0.048 \mathrm{Ra}^{\prime 0.27} \quad\left(\text { for } 10^{14} \leq \mathrm{Ra}^{\prime} \leq 2 \cdot 10^{16}\right) .
$$

Earlier, Theofanous et al. ${ }^{5}$ correlated mini-ACOPO data for downward heat transfer by the following correlations, as shown in Figure 5;

$$
\begin{array}{ll}
\mathrm{Nu}_{\mathrm{d}}=0.048 \mathrm{Ra}^{\prime 0.27} & \left(\text { for } 10^{12} \leq \mathrm{Ra}^{\prime} \leq 3 \cdot 10^{13}\right), \\
\mathrm{Nu}_{\mathrm{d}}=0.0038 \mathrm{Ra}^{\prime 0.35} & \left(\text { for } 3 \cdot 10^{13} \leq \mathrm{Ra}^{\prime} \leq 7 \cdot 10^{14}\right) .
\end{array}
$$

Equations (7) and (8) are identical correlations. Equation (7) can predict the ACOPO and mini-ACOPO data quite reasonably except in the Rayleigh number range of $3 \cdot 10^{13} \leq \mathrm{Ra}^{\prime} \leq 7 \cdot 10^{14}$. Mayinger et al. ${ }^{9}$ developed the following correlation for downward heat transfer based on their numerical solution of the natural convection problem;

$$
\mathrm{Nu}_{\mathrm{d}}=0.55 \mathrm{Ra}^{\prime 0.2} \quad\left(\text { for } 7 \cdot 10^{6} \leq \mathrm{Ra}^{\prime} \leq 5 \cdot 10^{14}\right) .
$$

Figures 6 and 7 compare the predictions by Equation (10) with the data from mini-ACOPO, ACOPO, Asfia and Dhir ${ }^{10}$, and numerical results of Kelkar et al. ${ }^{11}$ It can be seen from Figure (6) that Equation (10) has a significantly different slope than the data. In fact, Equation (9) appears to be a better fit to the data. In Figure (7), although the data are bounded by Equation (10) and Equation (8). Therefore, there appears to be no advantage of using Equation (10) over Equations (8) or (9). Based on these observations, Equation (10) will not be used for our analysis. 


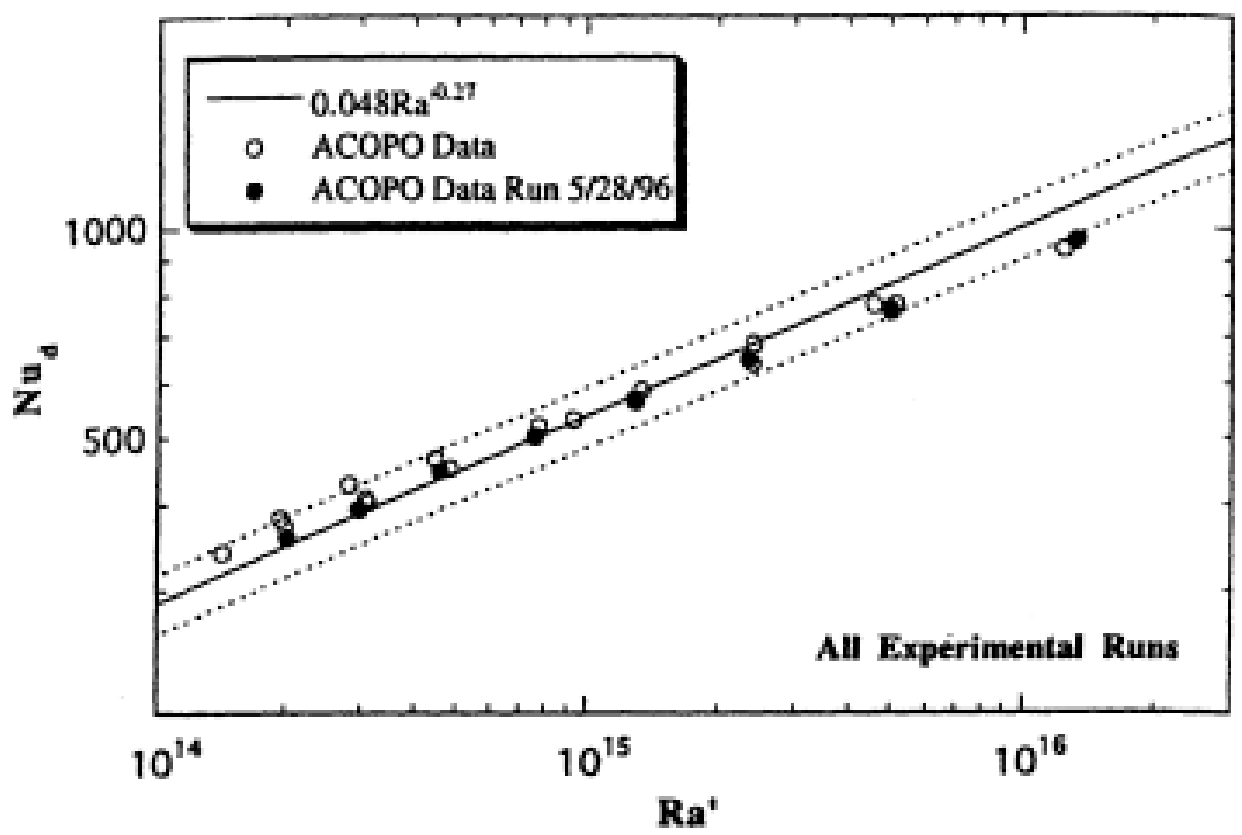

Figure 4. Downward heat transfer data correlation by Theofanous et al. ${ }^{8}$

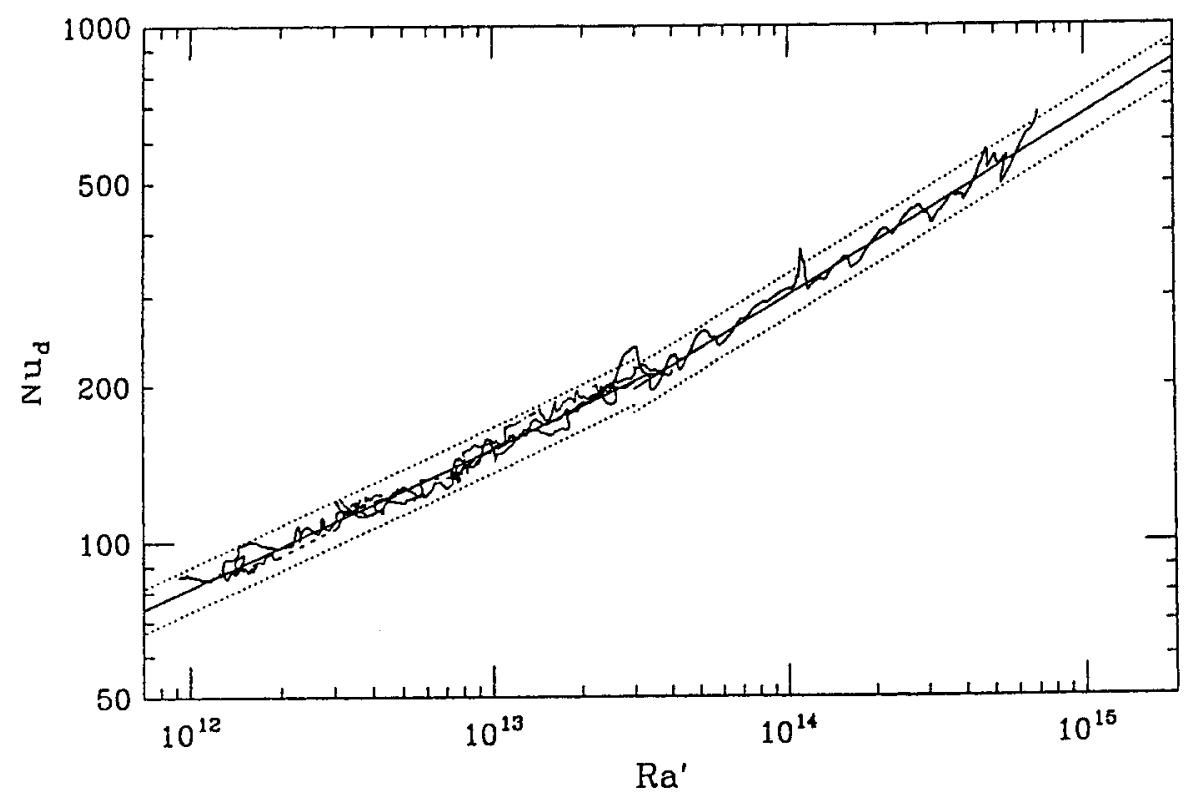

Figure 5. Correlation (Equations 8 and 9) of mini-ACOPO data for downward heat transfer by Theofanous et al. ${ }^{5}$ 


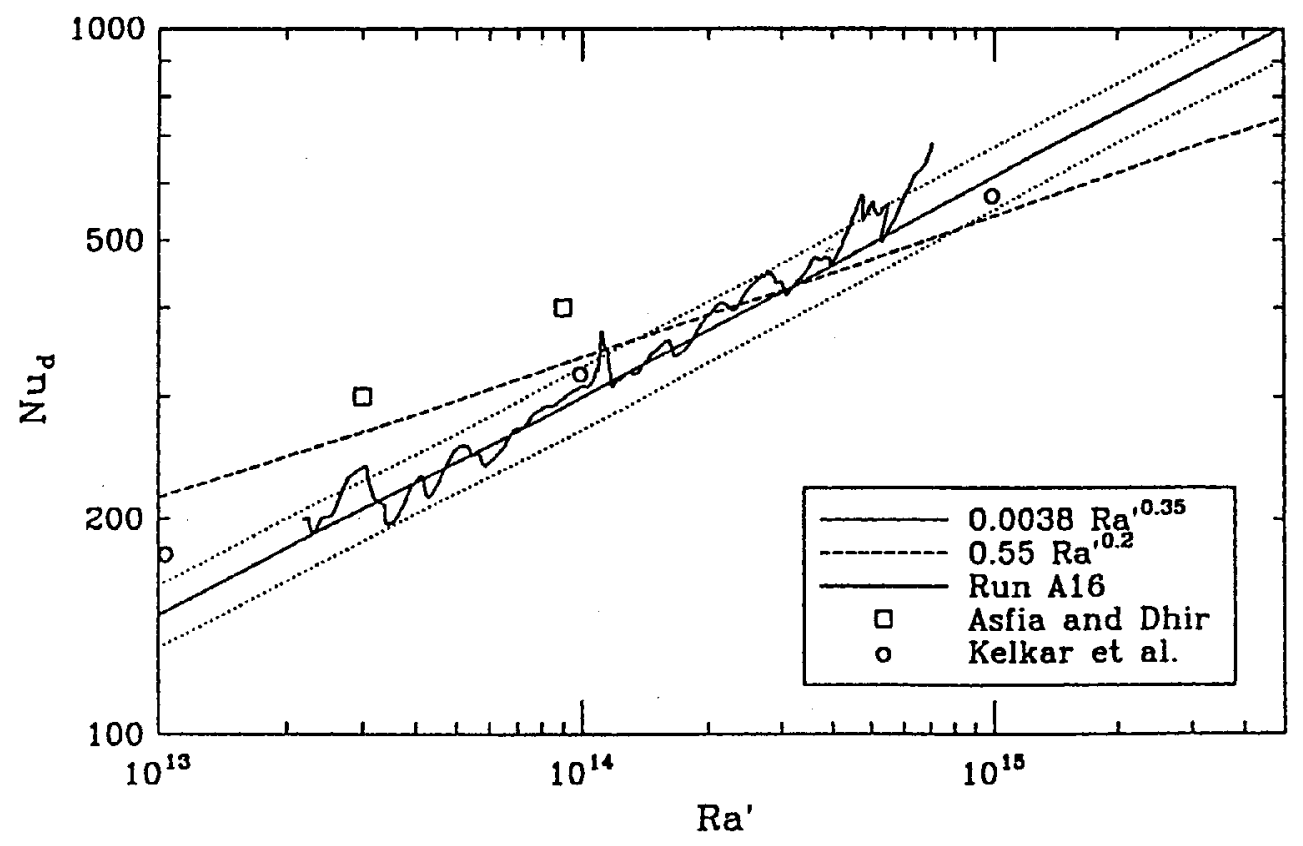

Figure 6. Comparison of Equations (10) predictions with experimental data and numerical results for downward heat transfer ${ }^{5}$.

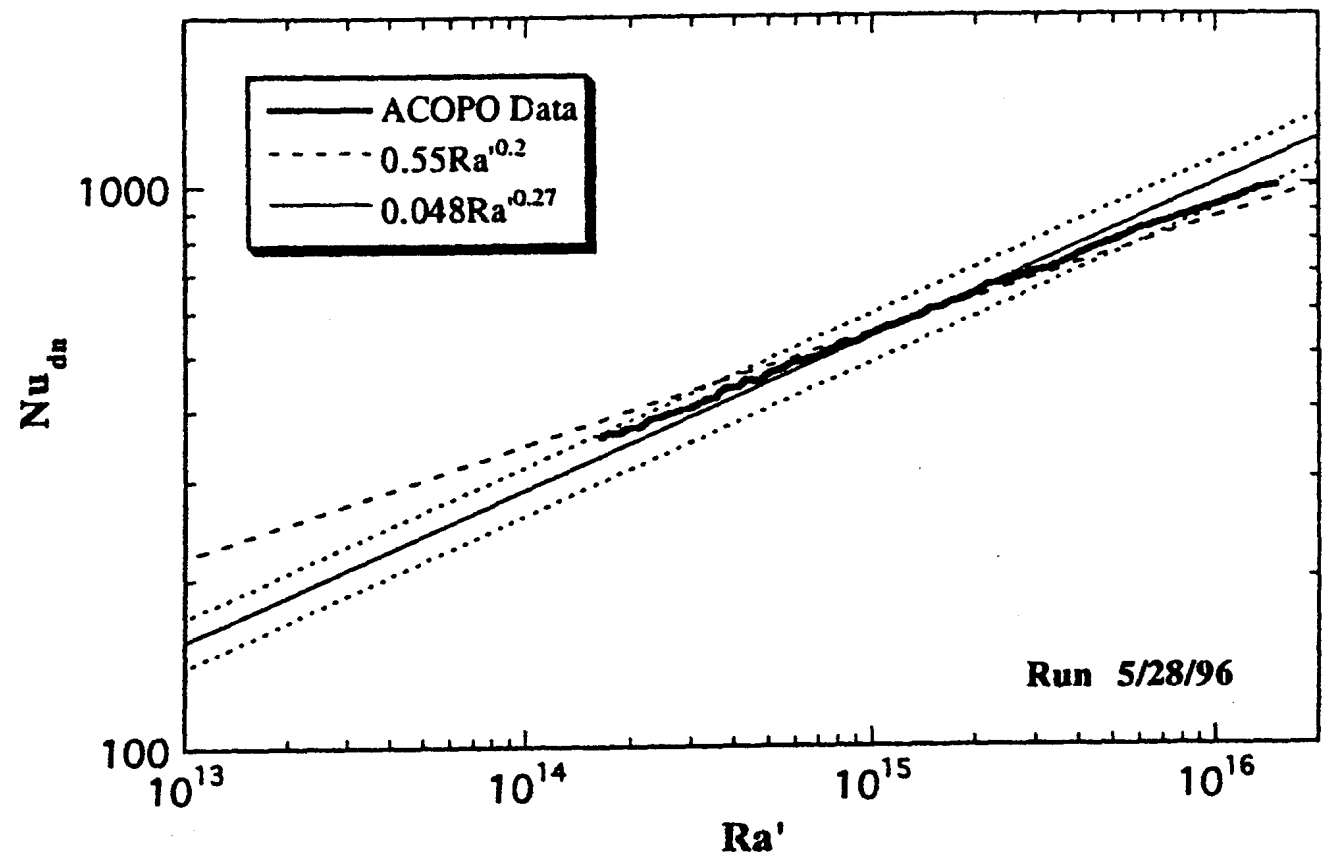

Figure 7. Comparisons of Equation (10) predictions with ACOPO data for downward heat transfer 5 . 


\subsubsection{Natural Convection in a Pool with no Internal Heat Generation}

If stratification takes place in a molten pool of the nuclear reactor, molten metal collects above the corium pool. Molten metal has no internal heat generation, but is heated by the corium pool from below. Therefore, in this case, the "external" Rayleigh number, Ra, will be applicable for natural convection heat transfer correlations.

One of the earliest correlations for natural convection between two horizontal plates is by Globe and Dropkin ${ }^{12}$. However, recently Park et al. ${ }^{13}$ performed experiments to simulate a molten metal pool in a nuclear reactor. It was determined that although Globe and Dropkin's correlation, given in Equation (11) does reasonable job of fitting their data, their new correlation, given in Equation (12), is somewhat better. This fact can be seen in Figure (8). The Globe and Dropkin and the Park et al. Correlations are;

$$
\begin{aligned}
& \mathrm{Nu}_{\mathrm{u}}=0.051 \mathrm{Ra}^{1 / 3}, \\
& \mathrm{Nu}_{\mathrm{u}}=0.0923 \mathrm{Ra}^{0.302} \quad\left(\text { for } 2 \cdot 10^{4} \leq \mathrm{Ra} \leq 2 \cdot 10^{7}\right) .
\end{aligned}
$$

Theofanous et al. ${ }^{5}$ has also recommended using a correlation like that in Equation (11). Based on the work by O'Toole and Silveston ${ }^{14}$, for a Prandtl number of 0.13 , Theofanous et al. ${ }^{5}$ arrived at the following correlation;

$$
\mathrm{Nu}_{\mathrm{u}}=0.088 \mathrm{Ra}^{0.305}
$$

Correlation in Equation (13) is nearly the same as given by Park et al. ${ }^{13}$ in Equation (12). It should also be noted that Park et al. ${ }^{13}$ have defined the "external" Rayleigh number with characteristic length being equal to the height of the liquid metal pool.

For the molten metal pool, no experimentally verified correlation exists for the heat transfer (Nusselt number) in the horizontal direction to the vertical vessel walls. Therefore, the Nusselt number can be estimated by using either Equation (5) with a different definition of Rayleigh number ( $\mathrm{Ra}$ ) or Equation (12). There is no experimental data to test the validity of either correlation. Equations (5) and (12) give the same results near $\mathrm{Ra}=10^{7}$. Because slopes of the two correlations are different $(0.19$ versus 0.302$)$, Equation (5) will give higher values of $\mathrm{Nu}_{\mathrm{h}}$ for $\mathrm{Ra}<10^{7}$. Whereas for $\mathrm{Ra}>10^{7}$, Equation (12) will give higher value of $\mathrm{Nu}_{\mathrm{h}}$. Therefore, at present it is suggested that an average of Equations (5) and (12) be used, which is;

$$
\mathrm{Nu}_{\mathrm{h}}=0.5\left(0.6 \mathrm{Ra}^{0.19}+0.0923 \mathrm{Ra}^{0.302}\right) \text {. }
$$




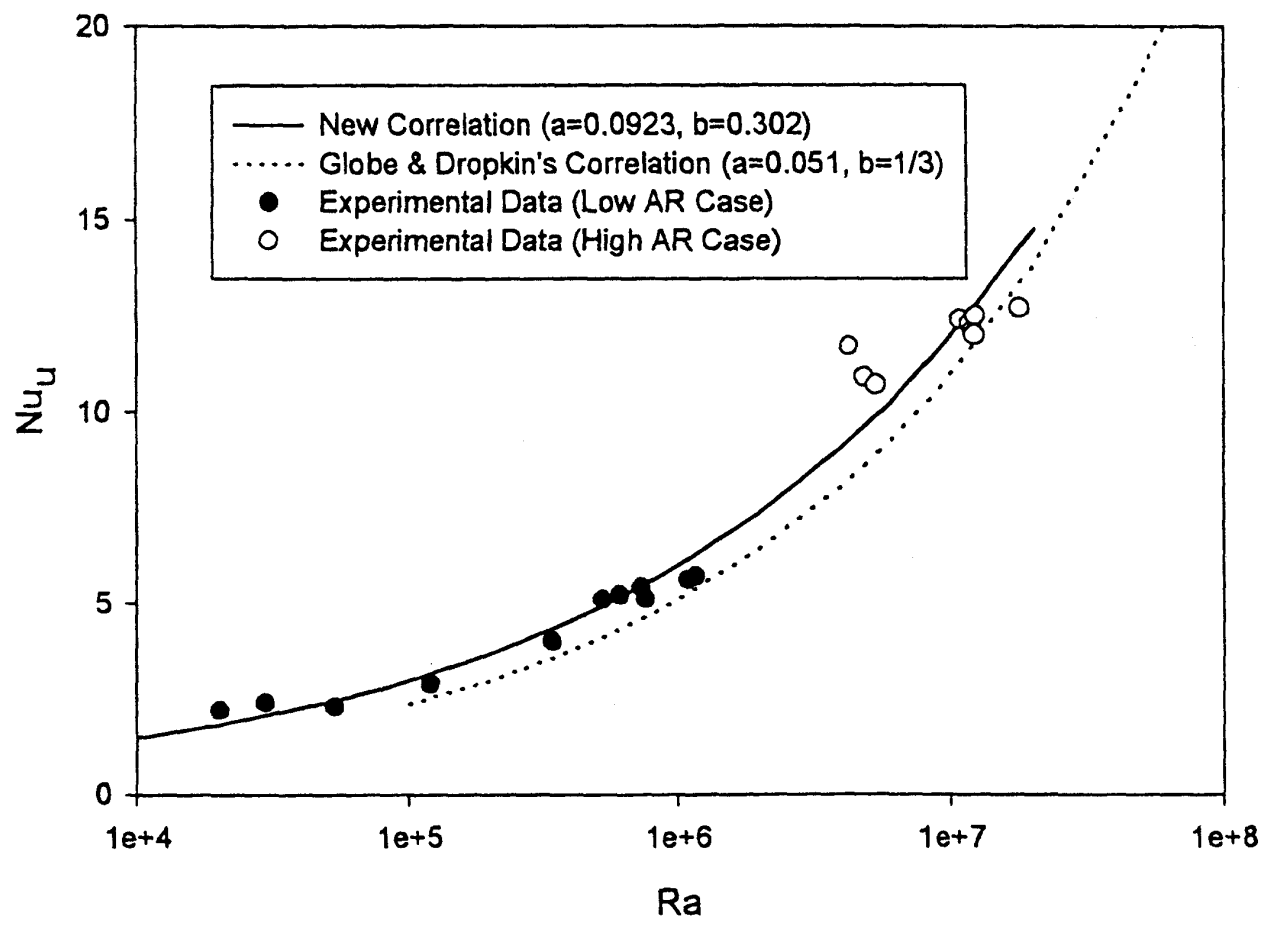

Figure 8. Natural convection upward heat transfer data and correlation by Park et al. ${ }^{13}$

\section{SELECTED NUSSELT NO. VERSUS RAYLEIGH NO. CORRELATIONS}

The previous section presented a summary of Nusselt number versus Rayleigh number correlations based on the experimental and numerical investigations. However, all the experiments are simulations using water or Freon. None of the experiments had two stratified pools, one representing corium and other representing molten metal.

Therefore, the correlations given in Table 1 represent best available information on the corium-metal pool natural convection heat transfer. Table 1 lists various correlations for natural convection Nusselt number in a hemispherical cavity with and without internal heat generation.

Table 1. Selected Nu vs. Ra Correlations

\begin{tabular}{|c|c|c|c|}
\hline & $\begin{array}{l}\text { Heat Transfer } \\
\text { Direction }\end{array}$ & $\mathrm{Nu}$ versus Ra Correlation & Rayleigh No. Range \\
\hline \multirow{3}{*}{$\begin{array}{l}\text { With Internal Heat } \\
\text { Generation } \\
\text { (Corium Pool) }\end{array}$} & Up & $\begin{array}{l}\mathrm{Nu}_{\mathrm{u}}=0.345 \mathrm{Ra}^{0.233} \\
\mathrm{Nu}_{\mathrm{u}}=0.9 \mathrm{Ra}^{\prime 0.2}\end{array}$ & $\begin{array}{l}10^{10} \leq \mathrm{Ra}^{\prime} \leq 3.7 \cdot 10^{13} \\
10^{14} \leq \mathrm{Ra}^{\prime} \leq 10^{17}\end{array}$ \\
\hline & Down & $\begin{array}{l}\mathrm{Nu}_{\mathrm{d}}=0.048 \mathrm{Ra}^{\prime 0.27} \\
\mathrm{Nu}_{\mathrm{u}}=0.345 \mathrm{Ra}^{\prime 0.233}\end{array}$ & $\begin{array}{l}10^{12} \leq \mathrm{Ra}^{\prime} \leq 3 \cdot 10^{13} \\
10^{14} \leq \mathrm{Ra}^{\prime} \leq 2 \cdot 10^{16} \\
3 \cdot 10^{13} \leq \mathrm{Ra}^{\prime} \leq 7 \cdot 10^{14}\end{array}$ \\
\hline & Horizontal & $\begin{array}{l}\mathrm{Nu}_{\mathrm{h}}=0.6 \mathrm{Ra}^{\prime 0.19} \\
\mathrm{Nu}_{\mathrm{h}}=0.85 \mathrm{Ra}^{\prime}{ }^{0.19}\end{array}$ & $\begin{array}{l}10^{7} \leq \mathrm{Ra}^{\prime} \leq 10^{10} \\
5 \cdot 10^{12} \leq \mathrm{Ra}^{\prime} \leq 10^{14}\end{array}$ \\
\hline \multirow{2}{*}{$\begin{array}{l}\text { Without Internal Heat } \\
\text { Generation (Metal } \\
\text { Layer) }\end{array}$} & Up & $\mathrm{Nu}_{\mathrm{u}}=0.0923 \mathrm{Ra}^{0.302}$ & $2 \cdot 10^{4} \leq \mathrm{Ra} \leq 2 \cdot 10^{7}$ \\
\hline & Horizontal & $\begin{aligned} \mathrm{Nu}_{\mathrm{h}}= & 0.5\left(0.6 \mathrm{Ra}^{0.19}+\right. \\
& \left.0.0923 \mathrm{Ra}^{0.302}\right)\end{aligned}$ & \\
\hline
\end{tabular}


It can be noticed in Table 1 that experimentally verified correlations do not exist for every value of Rayleigh number in the range $10^{4}-10^{17}$. Therefore, in the Rayleigh number range for which Nusselt number is not known, a reasonable extrapolation of nearest available correlation has to be made. For natural convection heat transfer in the horizontal direction in the metal layer, no well-tested correlation is available. Therefore, an average of two correlations is being suggested. The surface area of the vertical walls in contact with the metal layer is small relative to the surface area for heat transfer in the vertical direction, it is expected that even an approximate value of Nusselt number in the horizontal direction would not introduce any significant error.

\section{IMPLEMENTATION OF STRATIFIED HEAT TRANSFER MODEL INTO COUPLE MODEL}

The COUPLE model in SCDAP/RELAP5 calculates the transient temperature distribution in the lower head of a reactor vessel and in the solid and molten debris supported by the lower head. The user has the option of choosing either a homogeneous or a stratified molten pool. If the pool containing partial or completely molten core material is homogeneous, COUPLE, will calculate heat transfer in the region in an existing algorithm. The only change will be that some Nusselt number correlations may have to be modified. If the user chooses to have two stratified pools, it is proposed that full use of existing model COUPLE be made. The model, COUPLE, uses the effective thermal conductivity concept of each computational cell to calculate the heat transfer behavior. It is proposed that in the modified computational scheme, the new natural convection heat transfer coefficient to calculate effective thermal conductivity be obtained from the correlations given in Table 1. The remainder of the calculation scheme would remain the same. Present numerical scheme to calculate conduction heat transfer and the growth of frozen corium or metal crust would also be retained.

In COUPLE, the transient temperature distribution is calculated by applying heat conduction equations for the lower head and for the regions with solidified or liquefied debris, and by applying correlations for natural convection heat transfer at the liquid-solid interface. The liquid-solid interface include the following locations; (1) molten corium pool facing sides of solidifed crust at the inner surface of the lower head, and (2) molten corium pool facing side of solidified material on top of corium pool.

Subroutine KPOOL in the COUPLE model will be generalized to account for heat transfer at the liquid-solid interface for a stratified molten pool. This subroutine calculates the heat flux due to natural convection on the molten pool side of liquid-solid interfaces. Currently, the subroutine calculates the heat flux only for liquid-solid interfaces for a homogeneous molten pool. The subroutine will be generalized to calculate the heat flux for stratified molten pools. For this case, the natural convection heat flux will be calculated for the following cases; (1) liquid-solid interface along inner surface of lower head and interfacing with molten ceramic material $\left(\mathrm{UO}_{2}\right.$ and $\left.\mathrm{ZrO}_{2}\right)$, (2) liquid-solid interface at top of molten ceramic material, (3) liquid-solid interface at inner 
surface of lower head and interfacing with molten metallic material, (4) liquid-solid interface at bottom of molten metallic layer, and (5) top surface of metallic layer.

Subroutine TGPSET in the COUPLE model will be generalized to calculate the average temperature of both molten ceramic and metallic regions. The average temperature of each molten region is applied to calculate the temperature differential term in the equation for heat flux at the molten pool side of the liquid-solid interface. Currently, the subroutine calculates only the average temperature of a well-mixed pool of molten corium. The average temperature is calculated by averaging the temperature of each contiguous finite element with molten material of identical composition. Molten material is represented as being well-mixed by applying a large multiplication factor to the conductivity of stationary molten material.

\section{ASSESSMENT OF THE MODEL}

In the literature, there are no data available for natural convection heat transfer for a corium pool with stratified metal pool above it. Even a simulated (water and/or Freon) stratified pools (one pool above another one) data are not available. The only available data available are for simulated hemispherical pool and a cylindrical pool simulating the molten metal pool. Moreover none of these pools are with a solidifying boundary. Therefore, in the absence of the desired data and noting that most of the selected correlations in Table 1 are based on the simulated experimental data, only some simple thought problems can be performed. One most important test will be to test if the energy is conserved in the corium and metal pools. Simple integrated energy balance equations can be written for the lower corium pool. Heat transferred to the upper metal pool must be equal to the heat generated in the lower corium pool (decay heat plus latent heat of fusion) minus heat loss and increase in sensible heat, if any. Other test problems can be generated based on the homogeneous numerical analysis of the lower pool by Kelkar et

al. $^{2}$, Schmidt et al. ${ }^{3}$, and O'Brien and Hawkes ${ }^{15}$. However, one has to select the problems that can be simulated by the SCDAP code. The numerical modeling mainly calculates temperature profile and heat flux in the hemispherical pool.

\section{CONCLUSIONS}

This report provides a simple model for incorporating formation of stratified pools in the lower head. An internal heat generating corium pool can form below a molten metal pool. Different natural convection heat transfer correlations were obtained for pools with and without internal heat generation. It was decided to make use of the existing COUPLE model and its algorithm to reduce the coding cost. Therefore, conduction heat transfer and solidification will be modeled with existing algorithms in COUPLE. Because no exact experimental data are available for stratified corium and molten metal pools, energy conservation and some simple problems will be used to test the model. 


\section{REFERENCES}

1. C. M. Allison, et al., SCDAP/RELAP5/MOD 3.2 Code Manual, Idaho National Engineering Laboratory Report NUREG/CR-6150, November 1996.

2. K. M. Kelkar, R. C. Schmidt, and S. V. Patankar, "Numerical Analysis of Laminar Natural Convection of Internally Heated Fluid in a Hemispherical Cavity," ANS Thermal Hydraulics Proceedings, 28th National Heat transfer Conference, San Diego, CA, August 9-12, 1992, pp. 355-364.

3. R. C. Schmidt, K. M. Kelkar, and S. V. Patankar, "Numerical Analysis of Laminar Natural Convection of Internally Heated Fluid in a Hemispherical Cavity with an Adiabatic Surface," 29th National Heat transfer Conference, Atlanta, GA, August 811, 1993, pp. 331-338.

4. S. K. Wang and A. Walton, "Transient Correlations for Internally Heated Fluids," Unpublished paper, 1996.

5. T. G. Theofanous, C. Liu, S. Additon, S. Angelini, O. Kymäläinen, and T. Salmassi, "In-Vessel Coolability and Retention of a Core Melt," Report DOE/ID-10460, Vol. 1, Chapter 5, July 1995.

6. U. Steinberner and H.-H. Reinke, "Turbulent Buoyancy Convection Heat Transfer with Internal Heat Source," Sixth International Heat Transfer Conference, Toronto, Canada, August 7-11, 1978, Vol.2, NC-21, pp. 305-311, Hemisphere Publishing Corp., Washington, DC.

7. O. Kymäläinen, H. Tuomisto, O. Hongisto, and T. G. Theofanous, "Heat Flux Distribution from a Volumetrically Heated Pool with High Rayleigh Number," Nuclear Engineering and Design, 149, 1994, pp. 401-408.

8. T. G. Theofanous, M. Maguire, S. Angelini, and T. Salmassi, "The First Results from the ACOPO Experiment," Proceedings of International Topical Meeting on Probabilistic Safety Assessment (PSA '96), Sept. 29-Oct. 3, 1996, pp. 1343-1350.

9. F. Mayinger, M. Jahn, H. H. Reineke, and V. Steinberner, Examination of Thermohydraulic Processes and Heat Transfer in a Core Melt, Bunesministerium für Forschung und Technologie (BMFT) Final Report RS 48/1, Vol. 1-5, Institüt für Verfahrenstechnik, Technical University of Hanover, FRG, July 1975.

10. F. J. Afsia and V. K. Dhir, "An Experimental Study of Natural Convection in a Volumetrically Heated Spherical Pool Bounded on Top with a Rigid Wall," in InVessel Coolability and Retention of a Core Melt, edited by Theofanous et al., Report DOE/ID-10460, Vol. 1, Appendix C, July 1995.

11. K. M. Kelkar, K. M. Khankari, and S. V. Patankar, Computational Modeling of Turbulent Natural Convection in Flows Simulating Reactor Core Melt, Report by Innovative Research, Inc. to Sandia National Laboratories, December 1993.

12. S. Globe and D. Dropkin, "Natural Convection Heat Transfer in Liquid Confined by Two Horizontal Plates and Heated from Below," J. Heat Transfer, 81, 1959, pp. 2428.

13. R.-J. Park, S.-B. Kim, H.-D. Kim, and S.-M. Choi, "Natural Convection Heat Transfer with Crust Formation in the Molten Metal Pool," Nuclear Technology, 127, 1999, pp. 66-80. 
14. J. L. O'Toole and P. L. Silveston, "Correlation of Convective Heat Transfer in Confined Horizontal Layers," AIChE Chemical Engineering Progress Symposium Series, 57(32), 1961, pp.81-86.

15. J. E. O'Brien and G. L. Hawkes, "Thermal Analysis of a Reactor Lower Head with Core Relocation and External Boiling Heat Transfer," $27^{\text {th }}$ National Heat Transfer Conference, Minneapolis, MN, AIChE Symposium Series, 87(283), 1991, pp. 159168. 